Mini-Review

\title{
Productivity profile of CNPq scholarship researchers in Physical Education
}

\author{
Ludmila Cotrim Fagundes $^{1}$ (D), Carolina Júnia Reis Paz ${ }^{1}$ (D), Daniel Antunes Freitas ${ }^{1}$ (D), \\ Wellington Danilo Soares ${ }^{2}$ \\ ${ }^{1}$ Universidade Estadual de Montes Claros, Medicina, Montes Claros, MG, Brasil. \\ ${ }^{2}$ Universidade Estadual de Montes Claros, Educação Física, Montes Claros, MG, Brasil.
}

\begin{abstract}
To categorize the profile of scientific productivity scholarship researchers of the National Council for Scientific and Technological Development (CNPq) in the area of Physical Education. This is a quantitative, cross-sectional, descriptive and correlational study, whose participants were researchers in Physical Education scholarship holders of research productivity from CNPq, between 2015 and 2019, evaluated from the lists of productivity scholarships in force at CNPq. Results were categorized for statistical analysis. We found 92 current research productivity grants. Of these, $75 \%$ are destined for men, $58.7 \%$ fall into the PQ-2 category and most are concentrated in the Southeast region. More than $50 \%$ of productivity scholarship counselors do not mentor any postdoctoral students, but rather advise between 1 and 3 doctoral and master's students. $22.2 \%$ of the Midwestern scholarship holders published more than 100 articles and in the Southeast, there are the largest producers of books and book chapters, and about $6 \%$ of scholarship holders in this region had more than 20 publications. It can be inferred that there was a higher concentration of Physical Education researchers in the southeast region, with a higher prevalence for males, concentrating the majority of scholarship holders in the PQ-2 area. Through the identification of the profile of the fellows in the Physical Education area, more effective criteria and forms can be better established in order to stimulate scientific production, as well as the demands for the promotion of new research proposals.
\end{abstract}

Keywords: physical education, statistic, researcher, scientific production, productivity.

\section{Introduction}

Scientific research plays a very relevant role in the development of critical thinking and the generation of new knowledge and new technologies in the academic environment $^{1}$. In Brazil, scientific production has expanded in recent years, as evidenced by the increase in indexed publications at the Institute for Scientific Information (ISI) and Scielo $^{2}$. Brazilian scientific production is today the 13 th largest in the world, accounting for about $2 \%$ of world production ${ }^{1}$.

One consequence of the greater participation in national scientific production is the increased demand for funding for research projects and the Research Productivity Grants2. Currently, one of the main public agencies for the promotion of academic scientific research is the National Council for Scientific and Technological Development $(\mathrm{CNPq})^{3}$.

CNPq is an agency of the Ministry of Science, Technology, and Innovation (MCTI) for the encouragement of scientific and technological research in Brazil. Created in 1951, its performance contributes to the recognition of Brazilian researchers and research institutions by the scientific community. In addition, CNPq provides a particular form of funding for researchers, called Research Pro- ductivity Fellowships ${ }^{1,4}$. The Research Productivity Fellowship is a financial recognition reserved for doctors who excel in their scientific production activities. according to $\mathrm{CNPq}$ normative criteria. It enables dedication to research with more features and recognition guarantees ${ }^{2}$.

For the granting of Research Productivity Grants, characteristics of the proponent and their proposals are evaluated, such as the scientific merit of the project; originality, importance and repercussion of the proposer's scientific production; technological, scientific and innovation contribution; human resources training; participation or coordination in research projects and / or networks; academic and scientific management; international participation of the proposer and participation as a scientific editor. Where relevant, they are also considered multidisciplinary approaches; social impact; prioritization of major national problems; interaction with society; communication with the productive park and sustainability and environmental conservation ${ }^{4}$.

Researchers are classified into 3 categories for this scholarship: Researcher 1, Researcher 2, Researcher 3 and Senior. To fall into the first category, one of the prerequisites is to have completed the doctorate at least 8 years ago, while in the second category it is necessary to have completed it at least 3 years ago. In the Senior cate- 
gory, the researcher must be at least 15 years old with a scholarship in category $1 \mathrm{~A}$ or $1 \mathrm{~B}$. In addition, category 1 is subdivided by levels (A, B, C, D) based on data from the last 10 years and comparison with other researchers, is the first level of category 1 intended only for researchers with notable scientific productivity. In Category 2, the preferred production over the last 5 years for granting the scholarship is evaluated and there is no subdivision in levels. However, the transitional $2 \mathrm{~F}$ fellowship was implemented in category 2 , which aims to strengthen researchers from emerging courses ${ }^{3,5}$.

Physical education is a relatively new area, being considered a scientific discipline only in the second half of the twentieth century. Sports Science was represented by analytical, empirical research, evaluation, measurement and kinanthropometry until 1985. Later, this Science came to be understood as Physical Education Science or Human Movement Science or Sports Science. Although these sciences do not mean the same, they had in common the inclusion of sports science in the field of science. Physical education is a discipline considered plural that includes questions that arise from the relationship between man, knowledge, culture, and society. It is inserted in the area of health sciences at $\mathrm{CNPq}^{1}$.

In recent years, several studies have proposed to evaluate the profile and scientific production of Brazilian researchers from $\mathrm{CNPq}$ in various academic areas ${ }^{1}$. The objective of the present research is to characterize the profile of the scholarship researchers of scientific productivity in Physical Education of the National Council of Scientific and Technological Development.

\section{Methods}

This is a quantitative, cross-sectional, descriptive and correlational study, whose participants were scholarship holders of scientific productivity in Physical Education from CNPq, between 2015 and 2019, evaluated from the lists of productivity scholarships in force at CNPq.

The Lattes curricula of the researchers in question were accessed to categorize the following information: a number of articles published; number of postdoctoral students, doctoral students, master's students, and undergraduate scholarship students who guides; and number of book chapters published.

Data were cross-referenced with information on gender, Brazilian regions where the research productivity grants were allocated, and the productivity grant category (Senior, 1A, 1B, 1C, 1D, 2 and 2F). Data were tabulated and statistically analyzed.

\section{Results}

The search in the annual lists of $\mathrm{CNPq}$ productivity scholarships showed 92 research productivity scholarships in force in the area of Physical Education from 2015 to 2019. Of these, 23 were female and 69 males.
According to Table 1, which classifies the category of scientific productivity scholarships, there is a prevalence of category 2 scholarships, representing more than half $(58.7 \%)$ of the total productivity scholarships in the Physical Education area, while There was no scholarship in category $2 \mathrm{~F}$ and only one in Senior category.

From Table 2, it is inferred that women represent a minority of six out of seven types of scientific productivity scholarship, with a similar percentage of women at all levels. However, women are the only ones with senior fellowship, representing 100\% between 2015 and 2019 .

Table 3 shows that $58.7 \%$ of research productivity grants are concentrated in the Southeast region, followed by $28.3 \%$ in the South region. Midwest and Northeast together make up $13 \%$ of the scholarships. There are no records of productivity scholarships in the northern region of the country between 2015 and 2019 for the area of Physical Education.

Based on the number of orientations that the research productivity grantee has in percentage shown in Table 4 , most of them (63\%) do not advise any Postdoctoral student. With regard to $\mathrm{PhD}$ students, 59.8\% of

Table 1 - Productivity scholarship category.

\begin{tabular}{ccc}
\hline Category & $\mathbf{n}$ & $\mathbf{\%}$ \\
\hline Senior & 1 & $1 \%$ \\
$1 \mathrm{~A}$ & 9 & $10 \%$ \\
$1 \mathrm{~B}$ & 4 & $4,3 \%$ \\
1C & 5 & $5,4 \%$ \\
1D & 19 & $20,6 \%$ \\
2 & 54 & $58,7 \%$ \\
$2 \mathrm{~F}$ & 0 & $0 \%$ \\
\hline
\end{tabular}

Table 2 - Productivity scholarship category by gender.

\begin{tabular}{ccc}
\hline Category & Women (\%) & Men (\%) \\
\hline Senior & $100 \%$ & $0 \%$ \\
$1 \mathrm{~A}$ & $11 \%$ & $89 \%$ \\
$1 \mathrm{~B}$ & $25 \%$ & $75 \%$ \\
$1 \mathrm{C}$ & $20 \%$ & $80 \%$ \\
$1 \mathrm{D}$ & $26 \%$ & $74 \%$ \\
2 & $22 \%$ & $78 \%$ \\
$2 \mathrm{~F}$ & $0 \%$ & $0 \%$ \\
\hline
\end{tabular}

Table 3 - Brazilian region of origin.

\begin{tabular}{ccc}
\hline Region & $\mathbf{n}$ & $\mathbf{\%}$ \\
\hline Southeast & 54 & $58,7 \%$ \\
South & 26 & $28,3 \%$ \\
Northeast & 3 & $3,2 \%$ \\
North & 0 & $0 \%$ \\
Midwest & 9 & $9,8 \%$ \\
\hline
\end{tabular}


the scholarship counselors between 1 and 3 individuals. About $70 \%$ of scientific productivity fellows mentor between 1 and 3 Master's students. Scientific Initiation Fellows represent the highest orientation percentage with 10 or more students, yet this corresponds to $2.2 \%$ of scientific productivity fellows.

According to scientific articles in article format, the Midwest region of the country has the highest percentage of scholarship holders with more than 100 publications between 2015 and 2019. Most of the Northeast scholarship holders, $80 \%$, published between 10 and 55 articles, as well as in the Southeast and South, with a percentage of $67.3 \%$ and $69.5 \%$ respectively.

The Southeast region is identified as the largest producer of books and book chapters, being the only one to have productivity scholarship authors with more than 20 publications between 2015 and 2019. However, a significant part of the productivity scholarships of CNPq de generally had 10 or fewer books or chapter publications.

\section{Discussion}

The scientific productivity scholarships at $\mathrm{CNPq}$, regardless of areas of knowledge, include the reduction of the researchers' age range, especially for males ${ }^{6}$. Physical Education, analyzed within the Health Sciences, is encompassing dentistry, medicine, nursing, pharmacy, collective health, physical therapy, occupational therapy,

Table 4 - Number of people you guide.

\begin{tabular}{cccccc}
\hline Orientations & $\mathbf{0}$ & $\mathbf{1 - 3}$ & $\mathbf{4 - 6}$ & $\mathbf{7 - 9}$ & $\mathbf{\geq 1 0}$ \\
\hline Posdoctoral students & $63 \%$ & $37 \%$ & $0 \%$ & $0 \%$ & $0 \%$ \\
PhD students & $5,4 \%$ & $59,8 \%$ & $30,5 \%$ & $4,3 \%$ & $0 \%$ \\
Master students & $10,9 \%$ & $70,6 \%$ & $16,3 \%$ & $1,1 \%$ & $1,1 \%$ \\
Scientific Initiation Fellows & $46,7 \%$ & $42,4 \%$ & $6,5 \%$ & $2,2 \%$ & $2,2 \%$ \\
\hline
\end{tabular}

Table 5 - Articles published between 2015 and 2019 by region.

\begin{tabular}{cccc}
\hline Region & $\mathbf{1 0 - 5 5}$ & $\mathbf{5 6 - 1 0 0}$ & $>\mathbf{1 0 0}$ \\
\hline Southeast & $67,3 \%$ & $20 \%$ & $12,7 \%$ \\
South & $69,5 \%$ & $26 \%$ & $4,5 \%$ \\
Northeast & $80 \%$ & $20 \%$ & $0 \%$ \\
North & $0 \%$ & $0 \%$ & $0 \%$ \\
Midwest & $44,5 \%$ & $33,3 \%$ & $22,2 \%$ \\
\hline
\end{tabular}

Table 6 - Book chapters published between 2015 and 2019 by region.

\begin{tabular}{cccc}
\hline Region & $\mathbf{0 - 1 0}$ & $\mathbf{1 1 - 2 0}$ & $\mathbf{2 0}$ \\
\hline Southeast & $87,27 \%$ & $7,27 \%$ & $5,46 \%$ \\
South & $95,65 \%$ & $4,35 \%$ & $0 \%$ \\
Northeast & $80 \%$ & $20 \%$ & $0 \%$ \\
North & $0 \%$ & $0 \%$ & $0 \%$ \\
Midwest & $100 \%$ & $0 \%$ & $0 \%$ \\
\hline
\end{tabular}

speech therapy, and nutrition; it presents almost all recent productions and quotes ${ }^{7}$. Brazilian journals are the majority of the posts, although they are a minority in the upper strata of the area's Webqualis ${ }^{8}$. From 2015 to 2019, the productivity of physical educators did not deviate from the general gender standard, with $75 \%$ of the productivity scholarships belonging to males.

Until 2002, $33 \mathrm{CNPq}$ research productivity fellows were from the Physical Education area. Of these, 26 acted directly as teachers of postgraduate courses. Since scholarship grants depend on the merit of the researcher, it can be concluded that most researchers are leading the graduate system, guiding doctoral students, masters and undergraduate students. The number of productivity grants awarded to the area increased considerably in the year $2003^{9}$. In 2015 until 2019, 37\% of the research productivity fellows in the physical education area were supervisors of at least 1 postdoctoral student, about $60 \% .70 \%$ and $42 \%$ advisors from 01 to 03 Ph.D students, master's students, and undergraduate students, respectively. This demonstrates an active profile of scholarship holders in the undergraduate area, influencing other researchers, however, in view of the granting of scholarships that depends on the merit of the researcher, a more expressive number of students was expected.

In 2005, considering the areas Physical Education and Sport Sciences, more than half of the productions published by scholarship holders were represented by articles with an epidemiological matrix in the empirical-analytical category. Regarding the Higher Education Institution (HEI), the Federal University of Rio Grande do Sul, the Gama Filho University and the Paulista State University tied with the largest number of productions, highlighting the South and Southeast regions among the highest productivity scholarship holders. publications ${ }^{10}$. This fact remains in the period from 2015 to 2019, with the Southeast region holding more than half of the scholarships, followed by the South region, together making a total of 80 research productivity grants, out of 92 totals.

Between 2007 and 2009, most of the scholarship researchers in scientific productivity at $\mathrm{CNPq}$ in the Physical Education area had between 5 and 32 years of doctorate, were male, acting primarily in the southeast region, more specifically in the state of São Paulo. Most of the publications were published in national journals with Qualis B1, B2, and A2, as well as a large number of book and book chapter publications, as well as master's, doctoral and scientific initiation guidelines ${ }^{11}$. Between 2015 and 2019, productivity fellows from the Midwest region had the highest proportion of researchers with more than 100 article publications in the area of Physical Education, with the publication of books and book chapters highlighted by productivity fellows from São Paulo, the only region with researchers with more than 20 publications.

Regarding the areas of interest, Physical Education is subdivided into 11 subareas: Physical Activity and 
Health, Exercise Physiology, Sports Training, Biomechanics, Motor Behavior, Sport and Leisure, Kinanthropometry, Sociocultural Studies, Adapted Physical Activity, Professional Training, and Others. There are few studies on the sources of funding and the current dimension of the Physical Activity and Health subarea ${ }^{12}$, despite being the area of prominence in Physical Education Graduate Programs in Brazil ${ }^{13}$.

In this context of growth in the field of productivity in research in the field of Physical Education, this quantification of knowledge is addressed as a trend. Since in the other evaluation context, such as the qualitative Hirsch index (h) - which measures the productivity of articles and the impact of citations-based productions - it has limitations because it relates to longevity, ie, the researcher without a current scientific career The current one presents the constant $\mathrm{h}$ index, constituting a problem for beginning career researchers ${ }^{14}$.

\section{Conclusion}

Scientific research plays an important role in the generation of new knowledge. In Brazil, there was an expansion of scientific production which generated an increase in the demand for funding for research projects and for Scientific Production Scholarships, with CNPq being one of the main public research funding agencies. Physical education is a relatively new area within science and scientific knowledge and is inserted in the area of health sciences at CNPq.

There was a considerable increase in the number of scholarships awarded to the Physical Education area, with a total of 92 scholarships in force between 2015-2019. Most fellowships fall into category 2 and most fellows are male. The South and Southeast regions concentrate the largest number of scholarships, but the Midwest region has the most scholarship holders with more than 100 publications in article format. However, a large proportion of the South and Southeast scholarship holders concentrate in the category between 10-55 publications, a greater number than the Midwest region. Regarding the publication of book chapters, the Southeast region has the highest percentage of publications. Most of the oriented are scholarship holders of scientific initiation.

\section{Referências}

1. Leite BD, Oliveira EA, Queiroz IN, Martelli DR, Oliveira MC, Martelli Júnior H. Profile of the Researchers with Productivity Grants in the Brazilian National Research Council (CNPq) of the Physical Education Area. Motricidade. 2012;8(3):90-98.

2. Mendes PHC, Martelli DRB, Souza WP, Son SQ, Martelli Junior H. (2010). Profile of scientific productivity researchers in medicine at $\mathrm{CNPq}$, Brazil. Rev. bras. educ. med. 2010;34(4):535-541.

3. Weber JLA, Ramos CC, Mester A, Lindern D, Horlle KR, Souza CS et al. Profile of the scholarship researchers of sci- entific productivity in Psychology of the National Council of Scientific and Technological Development. Psychology Studies (Campinas). 2015;32(1):1-11.

4. National Council for Scientific and Technological Development (CNPq). RN-028/2015. Available at: http://memoria. cnpq.br/web/guest/view/-/journal_content/56_INSTAN CE_0oED/10157/2973312\#PQ.

5. Pedroso B, Pinto GMC, Picinin CT, Gutierrez GL. Analysis of the Technical-Scientific Production of the Productivity Scholarships of the CNPq of the Physical Education Area in the Triennium 2010-2012. Think the Practice. 2017;20 (4):719-733.

6. Guedes MC, Azevedo N, Ferreira L. O. Does scientific productivity have sex? A study on CNPq productivity fellows. Cadernos Pagu. 2016;45:367-399.

7. Wainer J, Vieira P. CNPq research productivity scholarship evaluation and bibliometric measurements: correlations for all major areas. Perspect Ciênc Inf. 2013;18(2):60-78.

8. Pedroso B, Picinin CT, Cantorani JRH. Production of productivity scholarship researchers in Physical Education in the 2010-2012 triennium: "Top 30" journals with the highest number of publications. Rev Bras Cineantropom. Desempenho Hum. 2016;18(6):731-6.

9. Kokubun E. Postgraduate degree in physical education in Brazil: objective indicators of challenges and perspectives. Rev Bras Cienc. Esporte. 2003;24(2):9-26.

10. Neto VM, Gunther MCC, Bossle F, Wittizorecki ES, Molina RMK. Reflections on the production of knowledge in physical education and sports science. Rev Bras Cienc. Esporte. 2006;28(1):145-65.

11. Leite BD, Oliveira EA, Queiroz IN, Martelli DR, Oliveira MC, Martelli JH. Profile of the Researchers with Productivity Grants in the Brazilian National Research Council (CNPq) of the Physical Education Area. Motri. 2012;8 (3):90-8.

12. Silva LL. Study of the Scientific Profile of CNPq Productivity Scholarship Researchers who work in Science and Mathematics Teaching. RBPEC. 2012;11(3):75-100.

13. Garcia L, Böhm A, Bacil E, Cruz M, Santo RE. The insertion of the Physical Activity and Health subarea in the Physical Education graduate programs in Brazil. Rev Bras Ativ Fis. e Saúde. 2014;19(2):215-22.

14. Vitor-Costa M, Silva PM, Soriano JB. The evaluation of research productivity in Physical Education: reflections on some limitations of bibliometric indicators. 2012;26(4):581-97.

\section{Corresponding author}

Ludmila Cotrim Fagundes Montes Claros State University. Av. Rui Braga S/N, Vila Mauriceia, Montes Claros, MG, Brazi.

E-mail: ludmilacotrimfagundes@gmail.com

Manuscript received on November 8, 2019

Manuscript accepted on November 13, 2019



Motriz. The Journal of Physical Education. UNESP. Rio Claro, SP, Brazil - eISSN: 1980-6574 - under a license Creative Commons - Version 4.0 